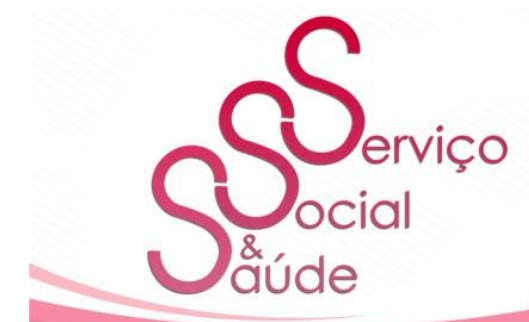

ISSN 2446-5992

(C) 100

doi: $10.20396 /$ sss.v19i0.8661084

RESENHA

\title{
Cuidados paliativos. Conheça-os melhor
}

\section{Palliative care. Get to know it better}

\author{
Hélia Bracons ${ }^{1}$ \\ Fernanda Ferreira ${ }^{2}$
}

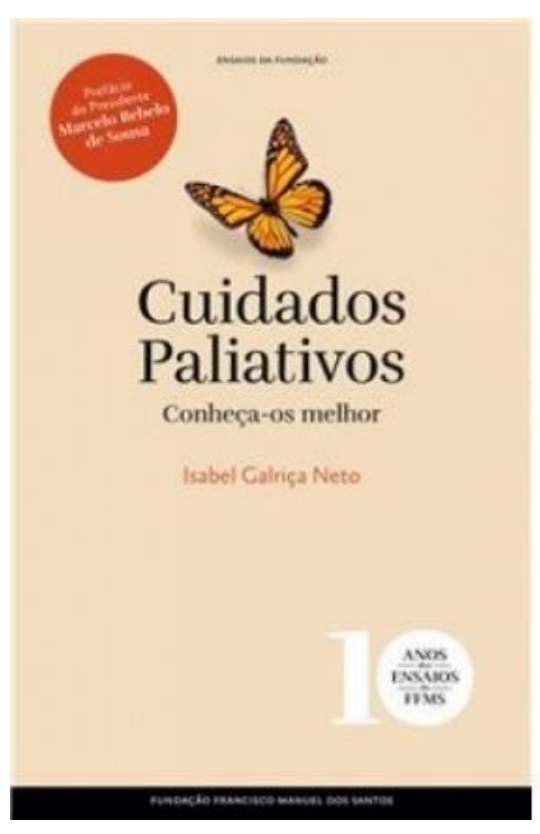

NETO, Isabel Galriça. Cuidados paliativos. Conheço-os melhor. Lisboa, Portugal: Fundação Francisco Manuel dos Santos, 2020. 103 p. ISBN: 9789899004573

\footnotetext{
${ }^{1}$ Professora Auxiliar do Instituto de Serviço Social da Universidade Lusófona de Humanidades e Tecnologias, Lisboa, Portugal. Doutora em Serviço Social. Diretora da Licenciatura em Serviço Social e Coordenadora dos Estágios. Telefone: 00351-966949451. E-mail: helia.bracons@ulusofona.pt

${ }^{2}$ Assistente Social no IPOFGL Instituto Português Oncologia Francisco Gentil, Lisboa. Pós-Graduada em Cuidados Paliativos. E-mail: feferreira@ipolisboa.min-saude.pt
}

\begin{tabular}{l|l|l|l|l|l}
\hline Serv. Soc. \& Saúde & Campinas, SP & v. 19 & $1-4$ & e020013 & e-ISSN 2446-5992 \\
\hline
\end{tabular}




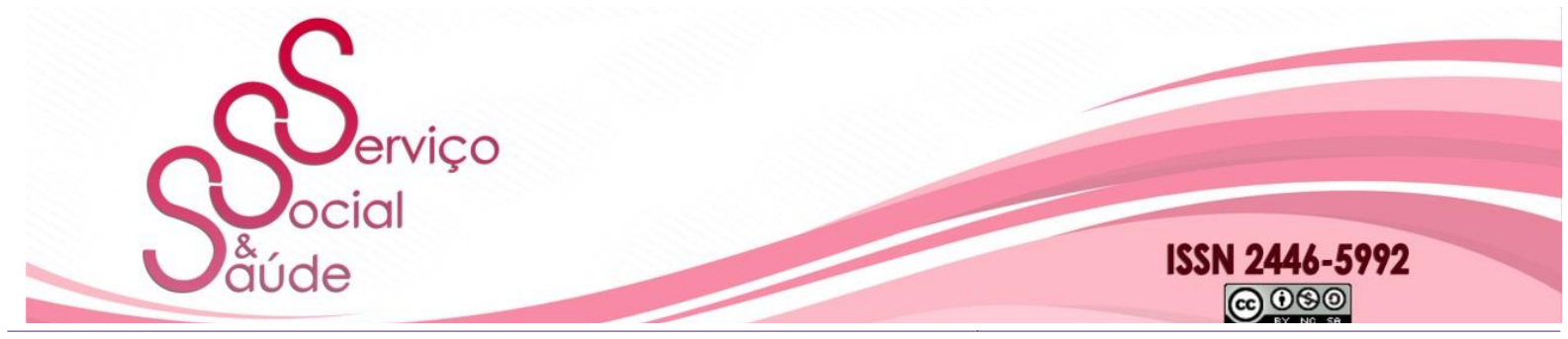

doi: $10.20396 /$ sss.v19i0.8661084

Este livro é o $n^{\circ} 103$ da Coleção Ensaios da Fundação, a qual é dedicada à divulgação e reflexão sobre temas relevantes do nosso tempo, no caso, Cuidados Paliativos. A sua importância é sublinhada pelo prefácio escrito pelo Presidente da República, Professor Marcelo Rebelo de Sousa.

A autora, Isabel Galriça Neto é médica desde 1985 e dedica-se aos cuidados paliativos há mais de 25 anos, isto é, trabalhando em diversas áreas de intervenção, sofrimento existencial e estratégias promotoras da dignidade nestes doentes; ética em fim de vida e sedação paliativa; comunicação com estes doentes, entre outras. Tem sido uma das principais vozes em Portugal desta especialidade.

Esta obra é uma reflexão sobre o impacto dos cuidados paliativos na prevenção e alívio dos problemas psicológicos, físicos, psicossociais e espirituais de pessoas em situação de doença crónica avançada, bem como no acompanhamento dos seus familiares e/ou cuidadores. É um ensaio, com uma linguagem simples, clara e de fácil leitura, que nos ajuda a compreender o que são cuidados paliativos e como estes surgiram, ilustrando com exemplos do seu quotidiano.

Procura contribuir para "ilustrar as necessidades de milhares de portugueses que todos os anos vivem com doenças crónicas e avançadas até morrer, e ajudá-los a ter uma Vida que valha a pena Viver" (p. 10). O livro está estruturado em quatro capítulos, inclui um glossário, bibliografia de referência e recursos de apoio.

No primeiro capítulo, O que são Cuidados Paliativos, começa por clarificar os conceitos enquadradores que nos ajudam a entender a gênese, a evolução e o enfoque destes, dando especial ênfase a uma prática de bons cuidados paliativos tendo como foco "cuidados de saúde rigorosos e humanizados [...] assentes na proteção da vida, centrados nos valores da pessoa doente, preservando e promovendo a sua dignidade e autonomia” (p. 40).

O segundo capítulo Cuidados Paliativos pediátricos, destaca a sua relevância e impacto em pessoas abaixo dos 18 anos. Reforça a ideia que é recomendável que estes 


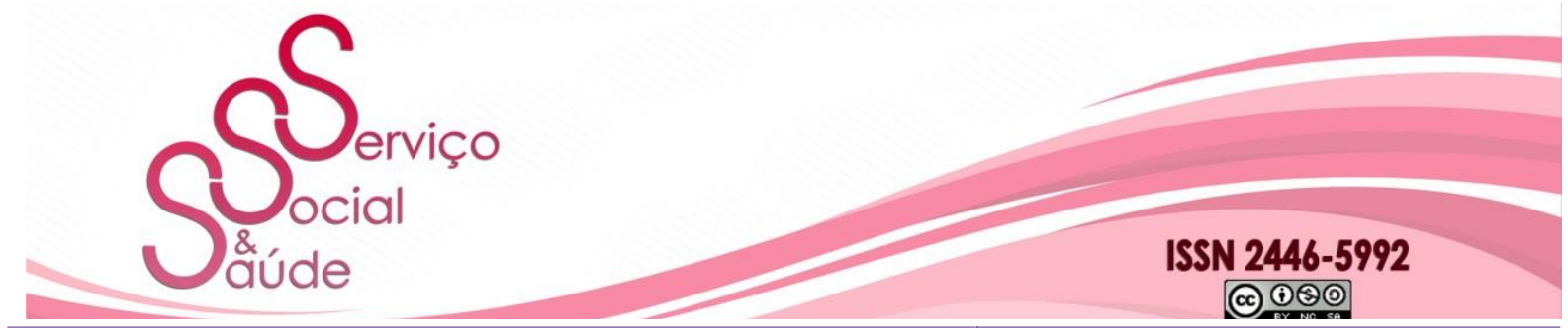

doi: $10.20396 /$ sss.v19i0.8661084

cuidados de saúde sejam oferecidos, numa fase precoce e não só em situação terminal ou de fim de vida. O objetivo central dos cuidados paliativos pediátricos é reduzir o sofrimento das crianças e das suas famílias. É reforçada a ideia de que o apoio aos cuidadores é essencial para que estes se sintam amparados e acompanhados.

O terceiro capítulo, Sofrimento em fim de vida, descreve as razões de sofrimento dos doentes, das famílias e/ou dos cuidadores e também dos profissionais de saúde. É reforçada a premissa que é imprescindível conhecer as dimensões que compõem essa realidade para se poder adequar os cuidados clínicos e de apoio prestados com vista a amenizar o sofrimento das pessoas em fim de vida. A autora refere que "os cuidados paliativos são a resposta transformadora para a vida destas pessoas e suas famílias, são o que lhes permite fazer dos últimos tempos de vida precisamente tempos de vida, tempos que, apesar das dificuldades, das dores (do corpo e da alma), não se sentiram desamparados, não experimentaram um sofrimento físico destrutivo, puderam encontrar sentido para o tempo que viveram" (p. 68).

O último capítulo, A necessidade e o acesso aos Cuidados Paliativos sublinha que estes deverão ser parte integrante do Sistema de Saúde porque constituem a resposta mais adequada para as necessidades de muitos doentes em situação de doenças crónicas e/ou incuráveis. Como refere, com o crescente envelhecimento populacional, o número de pessoas frágeis tem vindo a aumentar e estes serão o alvo preferencial dos cuidados de saúde: não só os idosos em fim de vida, mas muitos outros doentes, apontando, assim, para a necessidade de mais cuidados paliativos e da oferta de qualidade em Portugal - e no mundo - que possa dar uma resposta especializada a tantas pessoas, que deles necessitam.

Como reflexão final, a autora relembra que ajudar o doente a viver com a melhor qualidade possível, nunca deixando que o sofrimento se torne insuportável e preservar a dignidade, quanto possível, até ao seu fim, são os pilares fundamentais dos cuidados paliativos. 


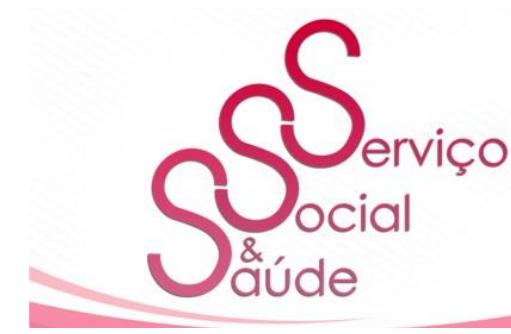

ISSN 2446-5992

(1) (1) (-)

doi: $10.20396 /$ sss.v19i0.8661084

É um contributo útil e fundamental para a compreensão desta realidade e como estes têm um papel transformador na vida das pessoas, ajudando a minorar o sofrimento em situações extremas de fim de vida. Sem dúvida, é uma obra que pretende também homenagear muitos doentes e famílias que passam por esta realidade. Diriamos, também, uma homenagem e agradecimento a todos os profissionais de saúde que, diariamente, trabalham e têm como missão a ajuda concreta, presente, próxima e colaborativa, a prestação de cuidados adequados com qualidade e a promoção e a preservação da dignidade da Pessoa em fim de Vida.

Recebido em junho de 2020 - Aprovado em junho de 2020.

\section{REFERÊNCIA}

NETO, I. G. Cuidados paliativos. Conheça-os melhor. Lisboa: Fundação Francisco Manuel dos Santos. 2020. 